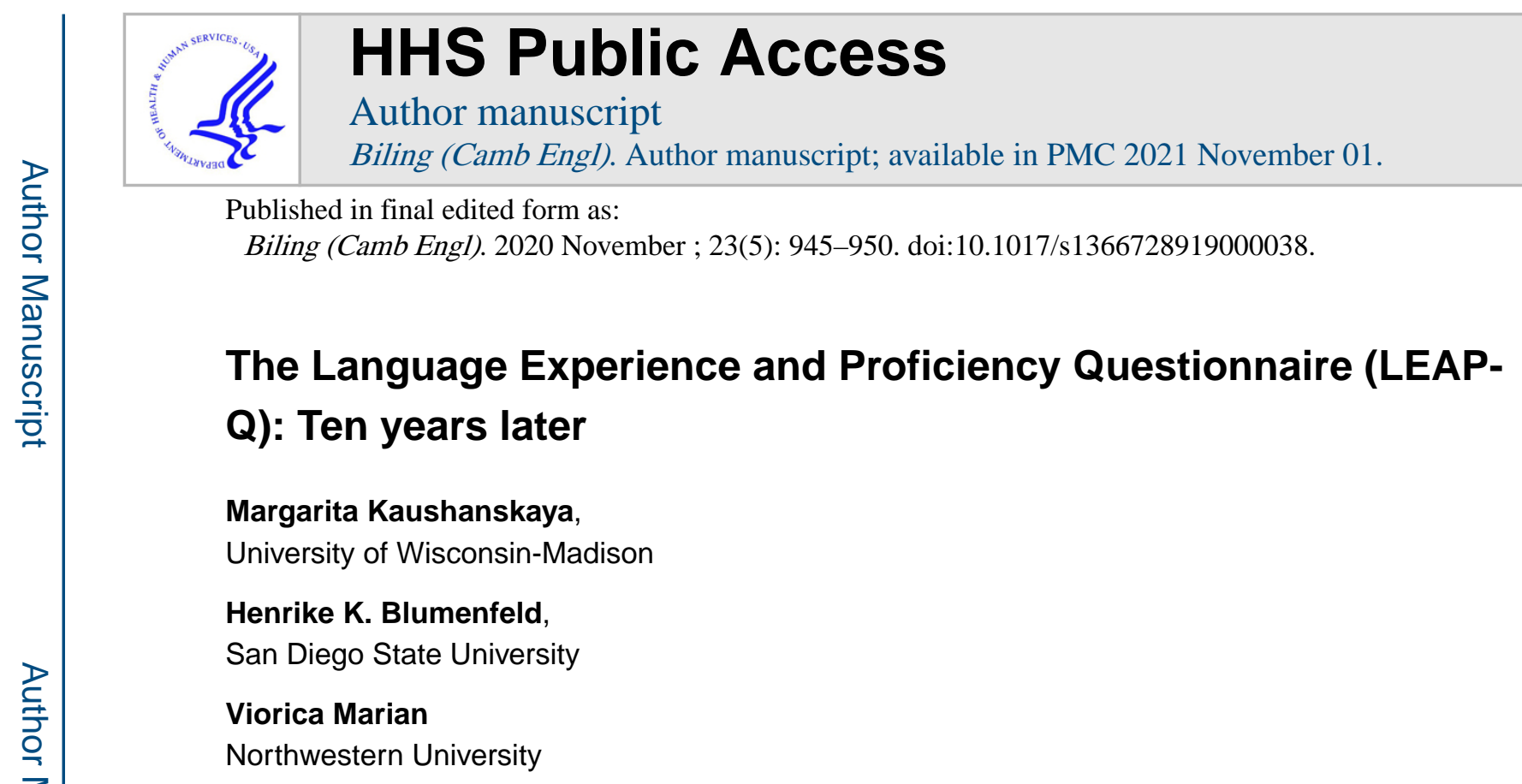

\begin{abstract}
The Language Experience and Proficiency Questionnaire (LEAP-Q) is a validated questionnaire tool for collecting self-reported proficiency and experience data from bilingual and multilingual speakers ages 14 to 80 . It is available in over 20 languages, and can be administered in a digital, paper-and-pencil, and oral interview format. The LEAP-Q is used by researchers across various disciplines (Psychology, Neuroscience, Linguistics, Education, Communication Sciences \& Disorders, etc.) to provide a comprehensive description of their bilingual participants, to substantiate a division of bilinguals into groups (e.g., early vs. late bilinguals), and to screen participants for adequate or threshold levels of language proficiency. Best practices for using the LEAP-Q include administration of the full questionnaire, consideration of acquisition and history of language use together with self-ratings of proficiency, and supplementation of self-reported data with objective language measures whenever possible. The LEAP-Q can be downloaded at no cost at https://bilingualism.northwestern.edu/leapq/.
\end{abstract}

\title{
Keywords
}

LEAP-Q; questionnaire; self-report; validation

The Language Experience and Proficiency Questionnaire (LEAP-Q) - a questionnaire tool for collecting self-reported background information on bilingual and multilingual speakers was developed in the Northwestern Bilingualism and Psycholinguistics Research Lab over the course of several years and was introduced in a paper published in the Journal of Speech, Language, and Hearing Research (Marian, Blumenfeld, \& Kaushanskaya, 2007). The original version of the LEAP-Q, all its translations and adaptions, and information on how to export the data can be accessed online at https://bilingualism.northwestern.edu/leapq/ at no cost to the research community.

Address for correspondence: Margarita Kaushanskaya, Waisman Center, 1500 Highland Avenue, Madison, WI 53705, Phone: (608) 263-5764; kaushanskaya@wisc.edu. 
We designed the LEAP-Q because at the time, there was little uniformity in how information about bilingual participants was presented in publications, and little agreement about which information was necessary to collect and present to enable replication (e.g., Li et al., 2006). Although to this day there is debate about the aspects of bilingual experience that are necessary in defining bilingual populations (e.g., Bedore et al., 2012; Dunn \& Tree, 2009; Gollan et al., 2012; Luk \& Bialystok, 2013; Robinson Anthony \& Blumenfeld, 2018; Sheng, Lu, \& Gollan, 2014), there is also considerable consensus across researchers on the fundamentals. At minimum, any work in bilingualism published today strives to include the following information: The ages at which the bilinguals' two languages were acquired; the extent of exposure to the two languages currently and over a lifetime; and estimates of dominance and/or proficiency (subjective, objective, or both). The publication of the LEAP$\mathrm{Q}$ played a significant role in engendering this change.

\section{How does it work?}

The LEAP-Q enables collection of self-reported language proficiency and experience data for any number of languages spoken by an individual. The LEAP-Q was designed to collect both broad measures of language dominance, language exposure, and language preference, and specific measures associated with each language (ages of acquisition and ages of attained fluency; length of immersion in different contexts; estimates of proficiency in speaking, reading, and understanding; ratings of how different contexts contribute to the acquisition of the language; extent of exposure to the language in different contexts; and degree of accent). See Figure 1 for a visual schematic. An 11-point (0-10) Likert scale is used for all the questions requiring estimates of degree and strength, with each point of the scale anchored to a descriptive label. The digital version of the LEAP-Q can be completed in 15 minutes by speakers of two languages. Knowledge of another language adds approximately 5 minutes to the completion of the questionnaire. The administration of the questionnaire as an oral interview extends administration time by 5-10 minutes.

The LEAP-Q was validated in two studies with two different samples of bilingual speakers. In Study 1, the LEAP-Q was administered to 52 multilingual speakers with diverse language backgrounds, representing 34 different languages. The internal validity of the questionnaire was established via a factor analysis that revealed logical clusters of questions reflecting fundamental bilingual dimensions (native language competence; second language competence; etc.). In Study 2, the LEAP-Q was administered to 50 bilingual speakers of English and Spanish. The internal validity of the questionnaire was replicated with this more homogenous sample of bilingual speakers. More importantly, criterion-based validity was established by confirming a relationship between self-reported data on the LEAP-Q and performance on objective, behavioral speech and language measures administered in the bilinguals' two languages (Reading Fluency, Oral Comprehension, Passage Comprehension, Productive Vocabulary, and Sound Awareness subtests of the Woodcock-Johnson/ Woodcock-Muñoz Tests of Achievement; Peabody Picture Vocabulary Test/Test de Vocabulario en Imágenes Peabody; and grammaticality judgment tasks).

Correlation analyses linked self-ratings of proficiency in the L1 and the L2 to performance scores on speech and language measures. The general pattern of correlations indicated 
stronger relationships for the $\mathrm{L} 2$ than for the L1, most likely because of the wider range of values for the L2, both in the self-reported proficiency data and in the behavioral performance data. Broad measures of language ability (reading and oral comprehension) correlated more strongly with the self-ratings of proficiency than more specific measures of language ability (vocabulary; sound awareness; etc.). This indicates that bilinguals' selfratings of their proficiency reflect gestalt approximations of language skill. In the L1, selfratings of reading proficiency were the strongest predictors of performance on speech and language measures. Conversely, in the L2, self-ratings of speaking proficiency were the strongest predictors of performance on speech and language measures.

\section{Who is it for?}

The original LEAP-Q was designed to be used in research settings, and to be administered to adult and adolescent bilingual and multilingual speakers representing a wide variety of language experiences and proficiency levels. In published studies, the youngest participants who successfully completed the LEAP-Q were 14 years of age (Krizman, Skoe, Marian, \& Kraus, 2014), and the oldest participants were 80 years of age (Ansaldo, Ghazi-Saidi, \& Adrover-Roig, 2015; Blumenfeld, Bobb, Schroeder, Freeman, \& Marian, 2016; Schroeder \& Marian, 2012). The 11-point rating scales make the LEAP-Q exquisitely sensitive to fluctuations in bilingual experience, and as a result, it can be successfully completed by highly proficient bilingual speakers (e.g., Conrad, Recio, \& Jacobs, 2011; Mercier, Pivneva, \& Titone, 2014; Pelham \& Abrams, 2014), as well as by very inexperienced L2 learners (Ettlinger et al., 2015; Nip \& Blumenfeld, 2015).

In the past 10 years, the LEAP-Q has become significantly more versatile. The LEAP-Q has been translated into 22 different languages (see Appendix A), and adapted for different dialects and socio-cultural contexts (e.g., English versions for the US, Australia, Singapore, and Canada). The LEAP-Q is now available in both an electronic and a paper-and-pencil format, and has been adapted as an oral interview to be used with older adult participants (e.g., Ansaldo et al., 2015), and with participants whose literacy levels are not strong enough (Blumenfeld, Quinzon, Alsol, \& Riera, 2017). Recently, the LEAP-Q was modified to enable collection of language background data from parents regarding their children (Rochanavibhata \& Marian, in preparation). All translations and adaptations of the LEAP-Q are available on https://bilingualism.northwestern.edu/leapq/. It is important to note that only the original LEAP-Q was validated against objective measures of speech and language ability.

\section{How is it used?}

Most frequently, the LEAP-Q is used by researchers to provide a comprehensive description of their bilingual participants (e.g., Ettlinger, Morgan-Short, Faretta-Studenberg, \& Wong, 2015; Leonard, Torres, Travis, Brown, et al., 2011), and to substantiate a division of bilinguals into groups and subgroups. For example, LEAP-Q data often form the basis for assigning and/or confirming the assignment of bilinguals to early/simultaneous vs. late/ sequential bilingual groups (e.g., Dimitropoulou, Duñabeitia, \& Carreiras, 2011; Pelham \& Abrams, 2014; Shi, 2010). The LEAP-Q is also often used by researchers to screen their 
bilingual participants for adequate levels of language proficiency (e.g., Conrad et al., 2011), to confirm native-speaker status (e.g., Hespos \& Piccin, 2009), high levels of language proficiency (e.g., Lidji, Palmer, Peretz, \& Morningstar, 2011), or to document differences in L1 vs. L2 language skills (e.g., Mor, Yitzahki-Amslalem, \& Prior, 2014). In some cases, it is required that threshold levels of proficiency be established for participating in a study. For instance, in studies requiring that only highly proficient bilinguals complete the experimental tasks, only participants who report proficiency levels of greater or equal to 7 (Stocco \& Prat, 2014) or 8 (Krizman et al., 2012) may be recruited.

At the same time, in a world where monolingualism is becoming less common, the LEAP-Q is increasingly often used to institute threshold levels of knowledge in a second language in defining monolingual participants. As is the case with using threshold levels to document high language proficiency, the levels used to document low levels of language proficiency also fluctuate. Thus, in some studies, a proficiency rating of 3 or below qualifies participants as monolinguals (e.g., Pelham \& Abrams, 2014), and in other studies a score of 4 is used for the same purpose (e.g., Ansaldo, Ghazi-Saidi, \& Androver-Roig, 2015).

Responses on the LEAP-Q tend to cluster together for particular types of bilinguals. For example, a beginner classroom L2 learner would be characterized by the following pattern of responses: A relatively small (less than $10 \%$ ) proportion of overall exposure to an L2, a relatively low preference for the L2 in speaking and reading situations (less than 10\%), a relatively late age of L2 acquisition (older than 12), an absence of a response for the questions regarding attained L2 fluency, lack of immersion in a country or a family where the L2 is spoken, relatively low levels of speaking L2 proficiency (less than 3, "fair"), and relatively low levels of naturalistic exposure to the L2 (less than 2). In contrast, a simultaneous bilingual who is also an active user of the two languages would be characterized by a very different pattern of responses: A relatively even (close to 50\%) proportion of overall exposure to an L2, a relatively balanced preference for the L2 in speaking and reading situations (around 50\%), an early age of L2 acquisition (birth to 3) as well as an early age of attained L2 fluency; immersion experiences in a country or a family where the L2 is spoken (at least 6 months), relatively high levels of L2 speaking proficiency (more than 7 "good"), and relatively high levels of naturalistic exposure to the L2 (more than 5). This holistic consideration of responses across the questionnaire is the best approach in identifying bilingual language profiles.

At the same time, answers on the LEAP-Q often do not fall neatly into a pattern. For instance, simultaneous bilinguals often report never attaining fluency, especially in reading, for the minority language. This is consistent with the literature suggesting partial attrition or incomplete acquisition in second-generation bilinguals (e.g., Montrul, 2016). It is also possible for bilinguals to report high levels of L2 proficiency despite relatively low levels of L2 preference, and a relative lack of current immersion experiences in one of their language. The LEAP-Q was not designed or validated to provide clusters of questions that would be informative with regard to bilingual sub-types. It then falls to each research team to make decisions about which answers of the LEAP-Q to take into account when characterizing their bilingual population, depending on the research question of interest. 
Ultimately, each research team can identify the particular threshold proficiency levels and / or other aspects of language experience to define their participants, depending on the nature of the research question and the characteristics of the bilingual population under study. Further, the focus of the research question may dictate that one particular self-rating of proficiency be prioritized as the defining bilingual characteristic. For instance, a critical threshold in reading proficiency may be set by researchers testing reading-related processes, while a critical threshold in speaking proficiency may be set by researchers examining language production.

Researchers have also combined responses from multiple questions on the LEAP-Q to obtain global proficiency indexes. For example, self-ratings of speaking, understanding and reading proficiency have frequently been averaged to yield a single composite proficiency score for each language (e.g., Dimitropoulou et al., 2011; Krizman et al., 2014; Reichle \& Birdsong, 2014; Marian, Chabal, Bartolotti, Bradley, \& Hernandez, 2014). The advantage of this approach is that it enables the researcher to avoid running multiple, and likely redundant tests when proficiency is entered into analyses as a predictor or an outcome variable. At the same time, it is common for some bilingual populations (e.g., L2 classroom learners; heritage speakers) to report higher levels of proficiency understanding than speaking L2. Such discrepancies in proficiency ratings may pose challenges to aggregating across proficiency scores. While we ultimately leave the choice of a particular analytical strategy to each individual researcher, we recommend that researchers conduct factor or correlational analyses of their LEAP-Q data before combining responses obtained from the LEAP-Q into a single score. It is appropriate to combine variables into a single index only when they correlate with each other (e.g., Rubin, 2012). Across the two experiments in the initial validation study, we found that although general constructs captured by the LEAP-Q were stable, there was also variability in how the questions clustered together depending on the specific characteristics of the bilingual sample.

\section{Can it be modified?}

Because only the original LEAP-Q was validated against behavioral measures of speech and language ability, our recommendation is to administer the LEAP-Q in its entirety. We therefore discourage researchers from changing the wording of the questions, changing the question order, or inserting / deleting questions from the LEAP-Q. However, we encourage researchers to modify the LEAP-Q in ways that suit their purposes by adding questions at the end of the questionnaire. Several such modifications have been implemented. For example, Libben and Titone (2009) modeled their proficiency questions after the questions on the LEAP-Q, and used the 11-point proficiency scale to also collect bilinguals' selfratings of their translating ability, grammatical ability, and fluency. Reichle (2010) adapted the LEAP-Q to probe for pronunciation ability, in addition to speaking, understanding, and reading proficiency. Prior (2012) added questions about parental education to the original LEAP-Q in order to obtain information about participants' socioeconomic status. The LEAP-Q was also adapted to collect language proficiency and exposure data in a trilingual individual with aphasia before and after the stroke (Faroqi-Shah \& Waked, 2010). 


\section{Best practices for using the LEAP-Q.}

Because self-reported proficiency data collected via the LEAP-Q correlate with behavioral measures of speech and language performance (as reported in the original study), it is tempting to rely solely on bilinguals' self-reported proficiency when describing a bilingual sample. Self-reported proficiency data alone can sometimes meet the needs of a particular study (e.g., Athanasopoulos, Damjanovic, Burnand, \& Bylund, 2015; Garbin, Costa, Sanjuan, Forn, et al., 2011; Martin, Strijkers, Santestaban, Escera, et al., 2013; Sullivan \& Schatz, 2009). However, a comprehensive approach to assessing bilinguals is more likely to yield a reliable picture of bilinguals' language profiles. In the case of the LEAP-Q, the correlations between self-reported proficiency levels and performance on behavioral speech and language measures were moderate-to-strong for the L2, and weak-to-moderate for the L1. In the regression models where the behavioral measures of speech and language were used to predict self-rated levels of proficiency, the $R^{2}$ values ranged from 0.70 to 0.23 . That is, there was not a perfect alignment between self-ratings of proficiency and objective measures of speech and language ability. A study by Shi (2011) illustrates this point.

Shi (2011) tested the ability of LEAP-Q proficiency ratings to yield reliable estimates of bilinguals' performance on an English listening task. Those bilinguals who self-rated their English proficiency as 7 or above (highly proficient) tended to perform most similarly to the monolinguals on the listening task. However, there was a large number of false-positive cases - i.e., many participants rated themselves as highly proficient while performing rather poorly on the listening task. Crucially, consideration of other aspects of history (language dominance and age of acquisition) improved upon the use of proficiency scores in assigning bilinguals into groups that would align with their behavioral performance.

In the original publication, we suggested that researchers use aspects of bilinguals' language acquisition history (and not just self-ratings of proficiency) to characterize the bilingual participants. We continue to believe that this is the best practice. Furthermore, in our own work, we administer the LEAP-Q to characterize our bilingual participants, but whenever possible, we use objective metrics of language performance to confirm the proficiency or dominance profiles revealed by the LEAP-Q. We strongly encourage other researchers to do the same.

\section{Looking to the future.}

It is now standard to include measures of proficiency and experience in any research protocol that involves bilingual participants. Over the past 10 years, the LEAP-Q has been employed as such a measure across a wide range of academic disciplines, ranging from psycholinguistic studies (e.g., Bartolotti \& Marian, 2012; Blumenfeld, Bobb, \& Marian, 2016; Dimitropoulou et al., 2011; Mercier, Pivneva \& Titone, 2013; Shook \& Marian, 2012; Van Engen, 2010; Whitford \& Titone, 2012) to neuroimaging (e.g., Conrad et al., 2011; Leonard et al., 2011; Marian et al., 2014; Reichle \& Birdsong, 2014; Scherer, Fonseca, Amiri, Adrover-Roig et al., 2011; Yi, Maddox, Mumford, \& Chandrasekaran, 2014) and clinical research (e.g., Faroqi-Shah \& Waked, 2010; Mor, Yitzhaki-Amsalem, \& Prior, 2014; Summers, Gonzales, \& Pechak, 2015). Together with other questionnaire tools such as the 
Language History Questionnaire by Li and colleagues (2006; 2014), the Language and Social Background Questionnaire by Anderson et al. (2017), and the Language Exposure Assessment Tool for children by DeAnda, Bosch, Poulin-Dubois, Zesiger \& Friend (2016), the LEAP-Q has become part of the standard battery of background assessments in bilingualism research.

To date, the original LEAP-Q article has been cited over 800 times (see google scholar metrics at goo.gl/eDjxhn). As the field moves forward, we envision that the LEAP-Q will continue to play a central role in multifaceted examinations of the bilingual experience. It is likely that the use of LEAP-Q data will shift in step with the re-conceptualizations of bilingualism as a continuum (e.g., Luk \& Bialystok, 2013; Dunn \& Tree, 2009), and with changing trends in the research questions posed within the broad realm of bilingualism research. For example, specific aspects of bilingual proficiency and experience obtained from the LEAP-Q are used increasingly in a graded manner, often serving as continuous predictors of bilinguals' performance (e.g., Krizman et al., 2014; Mercier, Pivneva \& Titone, 2014; Reichle \& Birdsong, 2014). This approach, when appropriate, may ultimately yield more consistent findings across studies and populations.

Although the existing version of the LEAP-Q and its many translations and adaptations can continue to serve the needs of many researchers for some time, it is important to recognize the need to re-norm the questionnaire in the future, as well as to update it in relevant ways. For example, possible updates to the LEAP-Q that we are currently considering include addition of questions regarding code-switching practices and exposure to code-switching; addition of questions regarding language exposure through internet and media; and a validation of empirically-derived thresholds in proficiency, exposure, and ages-ofacquisition that would reliably separate bilinguals into sub-groups. Any of these, or other changes, would require another validation of the questionnaire against objective measures of language ability, as was done for the original LEAP-Q.

In conclusion, together with other instruments, the LEAP-Q can be a helpful tool to bilingualism researchers in identifying profiles of language proficiency and exposure that influence linguistic and cognitive processes and their neural underpinnings. As the LEAP-Q continues to be used, translated, adapted, and modified by scientists to meet their research needs, we will continue to maintain a publicly available repository of all LEAP-Q versions so that we can contribute to validation and replicability efforts in the bilingualism research community.

\section{Acknowledgments}

The present project was supported by NIDCD Grant R01 DC011750 to Margarita Kaushanskaya, and Grant NICHD 2R01 HD059858 to Viorica Marian. The authors wish to express gratitude to all of the researchers who have adopted, adapted, and translated the LEAP-Q, and to the participants who provided the norming data. We would also like to thank everyone who has assisted with data coding, data analyses, data management, and email correspondence related to the LEAP-Q. 


\section{Appendix}

\section{Appendix A.}

Translations of the LEAP-Q that are currently available. All versions can be accessed at https://bilingualism.northwestern.edu/leapq/

\begin{tabular}{|c|c|}
\hline Language & Translators \\
\hline Arabic & $\begin{array}{l}\text { University of Maryland's Center for Advanced Study of Language, CETRA Language Solutions, } \\
\text { and } \\
\text { Faiza Sultan, President of Translation4all, Inc. }\end{array}$ \\
\hline Catalan & Eloi Puig Mayenco and Susagna Tubau Muntañá, Universitat Autònoma de Barcelona \\
\hline \multirow[t]{2}{*}{ Dutch } & $\begin{array}{l}\text { For the Netherlands: Lisa Vandeberg, Erasmus University, adapted by Marilyn Hall, Northwestern } \\
\text { U. }\end{array}$ \\
\hline & For Belgium: Freya De Keyser, Ghent University, and Marilyn Hall, Northwestern University \\
\hline \multirow[t]{6}{*}{ English } & Marian, Blumenfeld \& Kaushanskaya, 2007 \\
\hline & Pencil-and-paper version: Marilyn Hall, Northwestern University \\
\hline & For Australia: Agens Au, James Cook University, \& Marilyn Hall, Northwestern University \\
\hline & For Singapore: Marilyn Hall, Northwestern University \\
\hline & For Switzerland: Mehdi Purmohammad, Universitat Bern, \& Max R. Freeman, Northwestern U. \\
\hline & For Canada: Zvaigne, Salem, Groleau, \& Milette, McGill University \\
\hline Farsi & Mahrokh Alamzadeh, Dr. Ali Ghanaie, \& Dr. Shahla Sharifi, Mashhad Ferdowsi U. \\
\hline Filipino/Tagalog & Maria Khristina Manueli, Theologische Hochschule Reutlingen \\
\hline $\begin{array}{l}\text { Finnish/ } \\
\text { Suomalainen }\end{array}$ & Ari Huta and Mika Laheenmaki, University of Jyväskylä \\
\hline \multirow[t]{3}{*}{ French } & $\begin{array}{l}\text { For France: Anjali Bhatara, Emilie Michaud, and Judith Gervain, Universite Paris Descartes and } \\
\text { CNRS }\end{array}$ \\
\hline & For Belgium: Arnaud Szmalec, Universite Catholique de Louvain \\
\hline & For Canada: Zvaigne, Salem, Groleau, \& Milette, McGill University \\
\hline German & Larissa Weigel and Monica Gonzalez-Marquez, Cornell University \\
\hline Hebrew & Anat Prior, University of Haifa \\
\hline Hungarian & Timea Kutasi, University of Edinburgh, UK, \& Zsuzsanna Maté \\
\hline Italian & Luca Bevacqua and Roberta Spelorzi, University of Edinburgh \\
\hline Japanese & Koji Miwa and Yoshino Okuma, University of Alberta, \& Yu Ikemoto, Kwansei Gakuin University \\
\hline Korean & Ju Young Min and Luca Onnis, University of Hawaii \\
\hline Malay & Tze Peng Wong, University of Nottingham Malaysia, and Rosyati M. Yaakub \\
\hline Mandarin & Mahire Yakup, Jun Wang, and Trenton Wilson, U. of Kansas \\
\hline Portuguese & Ana Paula Scholl and Ana Beatriz Areas da Luz Fontes, Federal University of Rio Grande do Sul \\
\hline Romanian & Ioana Tufar and Rebeca Ciupe, Babes-Bolyai University \\
\hline Russian & $\begin{array}{l}\text { Marina Belkina, Katy Borodkin, Olga Iukalo, and Mira Goral, Lehman College, City University of } \\
\text { New York, adapted by Marilyn Hall, Northwestern University }\end{array}$ \\
\hline \multirow[t]{4}{*}{ Spanish } & For the US: Rojas \& Iglesias, Temple University \\
\hline & $\begin{array}{l}\text { For Mexico: Alma Luz Rodriguez Lazaro, Natalia Arias-Trejo, and Alina Signoret Dorcasberro, } \\
\text { Universidad Nacional Autonoma de México }\end{array}$ \\
\hline & $\begin{array}{l}\text { For Spain (peninsular Spanish): Eloi Puig Mayenco, Universitat Autonoma de Barcelona, and } \\
\text { Jason }\end{array}$ \\
\hline & Rothman and Jorge González Alonso, University of Reading \& the Arctic University of Norway \\
\hline
\end{tabular}

Biling (Camb Engl). Author manuscript; available in PMC 2021 November 01. 


\begin{tabular}{ll}
\hline Language & Translators \\
\hline Turkish & Özlem Yüksel-Sökmen, The Graduate Center of the City University of New York, and Sercan \\
& Şerifoğlu, Haliç University, Istanbul \\
& Pencil-and-paper version: Illker Güzelordu, Eastern Mediterranean University \\
\hline Vietnamese & Hien Pham, University of Alberta, Canada, \& Quyen Nguyen, Vietnam National U., Hanoi \\
\hline
\end{tabular}

\section{References}

Anderson JA, Mak L, Chahi AK, \& Bialystok E (2018). The language and social background questionnaire: Assessing degree of bilingualism in a diverse population. Behavior Research Methods, 50, 250-263. [PubMed: 28281208]

Ansaldo AI, Ghazi-Saidi L, \& Adrover-Roig D (2015). Interference control in elderly bilinguals: Appearances can be misleading. Journal of Clinical and Experimental Neuropsychology, 37, 455470. [PubMed: 25641572]

Athanasopoulos P, Damjanovic L, Burnand J, \& Bylund E (2015). Learning to think in a second language: Effects of proficiency and length of exposure in English learners of German. The Modern Language Journal, 99(S1), 138-153.

Bartolotti J, \& Marian V (2012). Language learning and control in monolinguals and bilinguals. Cognitive Science, 36, 1129-1147. [PubMed: 22462514]

Bedore LM, Pena ED, Summers CL, Boerger KM, Resendiz MD, Greene K, Bohman TM, \& Gillam RB (2012). The measure matters: Language dominance profiles across measures in Spanish-English bilingual children. Bilingualism: Language and Cognition, 15(03), 616-629.

Blumenfeld HK, Bobb SC, \& Marian V (2016). The role of language proficiency, cognate status, and word frequency in assessment of verbal fluency in Spanish-English bilinguals. International Journal of Speech-Language Pathology, 18 (2), 190-201. doi: 10.3109/17549507.2015.1081288 [PubMed: 27172853]

Blumenfeld HK, Schroeder SR, Bobb SC, Freeman MR, \& Marian V (2016). Auditory word recognition across the lifespan: Links between linguistic and non-linguistic inhibitory control in bilinguals and monolinguals. Linguistic Approaches to Bilingualism, 6, 1/2, 119-146. doi 10.1075/ lab.14030.blu [PubMed: 29034012]

Blumenfeld HK, Quinzon SJR, Alsol C, \& Riera SA (2017). Predictors of successful learning in multilingual older adults acquiring a majority language. Frontiers in Communication. doi: 10.3389/ fcomm.2017.00023

Conrad M, Recio G, \& Jacobs AM (2011). The time course of emotion effects in first and second language processing: A cross-cultural REP study with German-Spanish bilinguals. Frontiers in Psychology, 2:351. [PubMed: 22164150]

DeAnda S, Bosch L, Poulin-Dubois D, Zesiger P, \& Friend M (2016). The Language Exposure Assessment Tool: Quantifying language exposure in infants and children. Journal of Speech, Language, and Hearing Research, 59, 1346-1356.

Dhaliwal SS, \& Stern TA (2011). Recognition of psychiatric symptoms and conditions in Latino patients. Primary Care Companion of CNS Disorders, 13 (6). doi: 10.4088/PCC.10f01060

Dimitropoulou M, Duñabeitia JA, Carreiras M (2011). Masked translation priming effects with low proficient bilinguals. Memory \& Cognition, 39, 260-275. [PubMed: 21264599]

Dunn AL, \& Tree JEF (2009). A quick, gradient bilingual dominance scale. Bilingualism: Language and Cognition, 12(03), 273-289.

Ettlinger M, Morgan-Short K, Faretta-Sudenberg M, \& Wong PCM (2015). The relationship between artificial and second language learning. Cognitive Science, 40, 1-26.

Faroqui-Shah Y, \& Waked AN (2010). Grammatical category dissociation in multilingual aphasia. Cognitive Neuropsychology, 27, 181-203. [PubMed: 20830631] 
Garbin G, Costa A, Sanjuan A, Forn C, Rodriguez-Pujadas A, Venura N, Belloch V, Hernandez M, \& Avila C (2011). Neural bases of language switching in high and early proficient bilinguals. Brain and Language, 119, 129-135. [PubMed: 21550652]

Gollan TH, Weissberger GH, Runnqvist E, Montoya RI, \& Cera CM (2012). Self-ratings of spoken language dominance: A multi-lingual naming test (MINT) and preliminary norms for young and aging Spanish-English bilinguals. Bilingualism: Language and Cognition, 15(3), 594.

Hespos S, \& Piccin TB (2009). To generalize or not to generalize: spatial categories are influenced by physical attributes and language. Developmental Science, 12, 88-95. [PubMed: 19120416]

Kirk NW, Fiala L, Scott-Brown KC, \& Kempe V (2014). No evidence for reduced Simon cost in elderly bilinguals and bidialectals. Journal of Cognitive Psychology, 26 (4), 640-648. doi: 10.1080/20445911.2014.929580 [PubMed: 25264481]

Krizman J, Marian V, Shook A, Skoe E, \& Kraus N (2012). Subcortical encoding of sound is enhanced in bilinguals and relates to executive function advantages. PNAS, 109, 7877-7881. [PubMed: 22547804]

Krizman J, Skoe E, Marian V, \& Kraus N (2014). Bilingualism increases neural response consistency and attentional control: Evidence for sensory and cognitive coupling. Brain and Language, 128, 34-40. [PubMed: 24413593]

Leonard MK, Torres C, Travis K, Brown TT, Hagler D Jr., Dale AM, Elman J, Halgren E (2011). Language proficiency modulates the recruitment of non-classical language areas in bilinguals. PLOS One, 6(3): e18240. [PubMed: 21455315]

Li P, Sepanski S, \& Zhao X (2006). Language history questionnaires: A web-based interface for bilingual research. Behavior Research Methods, 38, 202-210. [PubMed: 16956095]

Li P, Zhang F, Tsai E, \& Puls B (2014). Language History Questionnaire (LHQ 2.0): A new dynamic web-based research tool. Bilingualism: Language and Cognition, 17, 673-680.

Libben MR, \& Titone DA (2009). Bilingual lexical access in context: Evidence from eye movements during reading. Journal of Experimental Psychology: Learning, Memory, \& Cognition, 35, 381390.

Lidji P, Palmer C, Peretz I, \& Morningstar M (2011). Listeners feel the beat: Entrainment to English and French rhythms. Psychonomic Bulletin \& Review, 18, 1035-1041. [PubMed: 21912999]

Luk G, \& Bialystok E (2013). Bilingualism is not a categorical variable: Interaction between language proficiency and usage. Journal of Cognitive Psychology, 25(5), 605-621. [PubMed: 24073327]

Marian V, Chabal S, Bartolotti J, Bradley K, \& Hernandez AE (2014). Differential recruitment of executive control regions during phonological competition in monolinguals and bilinguals. Brain and Language, 139, 108-117. doi:10.1016/j.bandl.2014.10.005 [PubMed: 25463821]

Martin CD, Strijers K, Santesteban M, Escera C, Hartsuiker RJ, \& Costa A (2013). The impact of early bilingualism on controlling a language learned late: An ERP study. Frontiers in Psychology, 4:815. [PubMed: 24204355]

Mercier J, Pivneva I, \& Titone D (2014). Individual differences in inhibitory control relate to bilingual spoken word processing, Bilingualism: Language and Cognition, 17 (1), 89-117. doi:10.1017/ S1366728913000084

Montrul S (2016). Heritage language development. Connecting the dots. International Journal of Bilingualism. Online first DOI: 10.1177/1367006916654368

Mor B, Yitzhaki-Amsalem S, \& Prior A (2014). The joint effect of bilingualism and ADHD on executive functions. Journal of Attention Disorders, 19, 527-541. [PubMed: 24681900]

Nip I \& Blumenfeld HK (2015). Proficiency and linguistic complexity influence speech motor control and performance in Spanish language learners. Journal of Speech, Language and Hearing Research, 58(3), 653-68. doi:10.1044/2015_JSLHR-S-13-0299

Pelham SD, \& Abrams L (2014). Cognitive advantages and disadvantages in early and late bilinguals. Journal of Experimental Psychology: Learning, Memory, and Cognition, 40, 313-325.

Prior A (2012). Too much of a good thing: Stronger bilingual inhibition leads to larger lag-2 task repetition costs. Cognition, 125, 1-12. [PubMed: 22841300]

Reichle RV (2010). Judgment of information structure in L2 French: Nativelike performance and the Critical Period Hypothesis. International Review of Applied Linguistics, 48, 53-85. 
Reichle RV, \& Birdsong D (2014). Processing focus structure in L1 and L2 French: L2 proficiency effects on ERPs. Studies in Second Language Acquisition, 1-30. doi: 10.1017/ S0272263113000594

Robinson Anthony J, \& Blumenfeld HK (2018). Language dominance predicts cognate effects and inhibitory control in young adult bilinguals. Bilingualism: Language and Cognition, 1-17. doi:10.1017/S1366728918001013

Rochanavibhata S \& Marian V (in preparation). A cross-cultural comparison of mother-child communication in the United States and Thailand.

Rubin A (2012). Statistics for evidence-based practice and evaluation. Boston, MA: Cengage Learning.

Scherer LC, Fonseca RP, Amiri M, Adrover-Roig D, Marcotte K, Giroux F, Senhadji N, Benali H, Lesage F, \& Ansaldo AI (2011). Syntactic processing in bilinguals: An fNIRS study. Brain and Language. doi: doi:10.1016/j.bandl.2014.10.005.

Schroeder SR, \& Marian V (2012). A bilingual advantage for episodic memory in older adults. Journal of Cognitive Psychology, 24 (5), 591-601. [PubMed: 23175648]

Sheng L, Lu Y, \& Gollan TH (2014). Assessing language dominance in Mandarin-English bilinguals: Convergence and divergence between subjective and objective measures. Bilingualism: Language and Cognition, 17 (2), 364-383.

Shi L-F (2010). Perception of acoustically degraded sentences in bilingual listeners who differ in age of English acquisition. Journal of Speech, Language, and Hearing Research, 53, 821-835.

Shi L-F (2011). How "proficient" is proficient? Subjective proficiency as a predictor of bilingual listeners' recognition of English words. American Journal of Audiology, 20, 19-32. [PubMed: 21330649]

Shook A, \& Marian V (2012). Bimodal bilinguals coactivate both languages during spoken comprehension. Cognition, 124, 314-324. [PubMed: 22770677]

Stocco A, \& Prat CS (2014). Bilingualism trains specific brain circuits involved in flexible rule selection and application. Brain \& Language, 137, 50-61. [PubMed: 25156160]

Sullivan N, \& Schatz RT (2009). Effects of Japanese national identification on attitudes toward learning English and self-assessed English proficiency. International Journal of Intercultural Relations, 33, 486-497.

Summers C, Gonzalez E, \& Pechak C (2015). How should we prepare rehabilitation sciences students to work with low English-proficient Spanish-speaking patients? Journal of Allied Health, 44 (2), 17E-21E. [PubMed: 25743397]

Van Engen KJ (2010). Similarity and familiarity: Second language sentence recognition in first- and second-language multi-talker babble. Speech Communication, 52 (11-12), 943-953. doi: 10.1016/ j.specom.2010.05.002 [PubMed: 21179561]

Whitford V, \& Titone D, (2012). Second-language experience modulates first- and second-language word frequency effects: Evidence from eye movement measures of natural paragraph reading. Psychonomic Bulletin \& Review, 19, 73-80. doi: 10.3758/s13423-011-0179-5 [PubMed: 22042632]

Yi H-G, Maddox WT, Mumford JA, \& Chandrasekaran B (2014). The role of corticostriatal systems in speech category learning. Cerebral Cortex, 26 (4), 1409-1420. doi: 10.1093/cercor/bhu236 [PubMed: 25331600] 


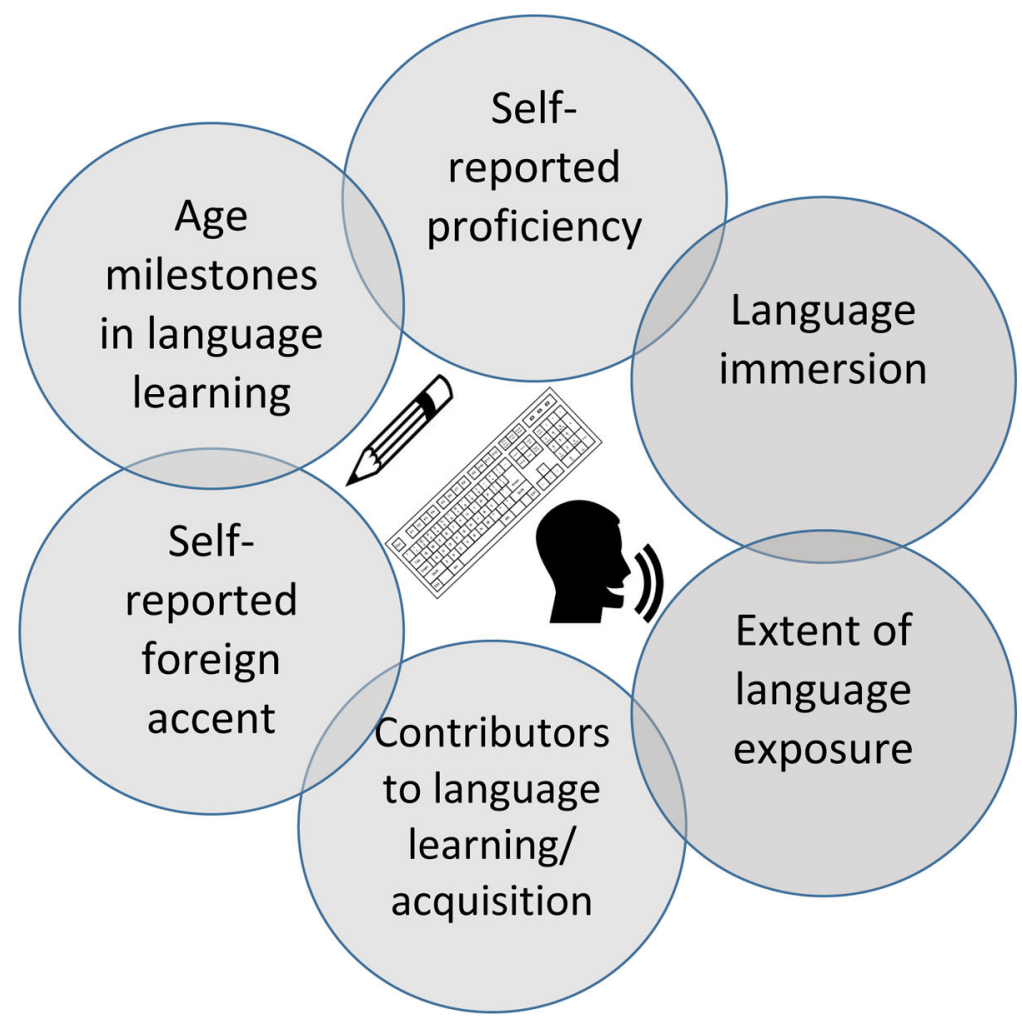

Figure 1.

The Language Experience and Proficiency questionnaire (LEAP-Q) is a self-report measure that can capture language profiles of multilingual speakers through self-reported proficiency, learning milestones, immersion duration, contributors to language learning/acquisition, extent of exposure and self-reported foreign accent, and can be administered as a pencil-andpaper, electronic or interview measure. 